\title{
Bedding control on landslides: a methodological approach for computer-aided mapping analysis
}

\author{
G. Grelle, P. Revellino, A. Donnarumma, and F. M. Guadagno \\ Dipartimento di Studi Geologici e Ambientali, Università del Sannio, via dei Mulini, 59/A, 82100, Benevento, Italy
}

Received: 3 September 2010 - Revised: 20 January 2011 - Accepted: 10 April 2011 - Published: 16 May 2011

\begin{abstract}
Litho-structural control on the spatial and temporal evolution of landslides is one of the major typical aspects on slopes constituted of structurally complex sequences. Mainly focused on instabilities of the earth flow type, a semi-quantitative analysis has been developed with the purpose of identifying and characterizing litho-structural control exerted by bedding on slopes and its effects on landsliding. In quantitative terms, a technique for azimuth data interpolation, Non-continuous Azimuth Distribution Methodological Approach (NADIA), is presented by means of a GIS software application. In addition, processed by NADIA, two indexes have been determined: (i) $\Delta$, aimed at defining the relationship between the orientation of geological bedding planes and slope aspect, and (ii) $C$, which recognizes localized slope sectors in which the stony component of structurally complex formations is abundant and therefore operates an evolutive control of landslide masses. Furthermore, some Litho-Structural Models (LSMs) of slopes are proposed aiming at characterizing recurrent forms of structural control in the source, channel and deposition areas of gravitational movements. In order to elaborate evolutive models controlling landslide scenarios, LSMs were qualitatively related and compared with $\Delta$ and $C$ quantitative indexes. The methodological procedure has been applied to a lithostructurally complex area of Southern Italy where data about azimuth measurements and landslide mapping were known. It was found that the proposed methodology enables the recognition of typical control conditions on landslides in relation to the LSMs. Different control patterns on landslide shape and on style and distribution of the activity resulted for each LSM. This provides the possibility for first-order identification to be made of the spatial evolution of landslide bodies.
\end{abstract}

Correspondence to: F. M. Guadagno (guadagno@unisannio.it)

\section{Introduction}

Geological and structural settings of slopes are the main predisposing factors controlling mass movement development (Fookes and Wilson, 1966; Zaruba and Mencl, 1969; Varnes, 1978). Bedding of lithologically or structurally complex sequences (sensu Esu, 1977; Vv. Aa.; 1985), stratigraphic or tectonic contacts between rocks with different geomechanical properties, and zones of intense fracturing linked to the presence of axes of folds and faults are all geological conditions at the basis of structural control (e.g. Guzzetti et al., 1996; Irfan, 1998; Scheidegger, 1998; Cruden, 2000; Martino et al., 2004; Margielewski, 2006; Prager et al., 2009). The definition of these elements at different scales plays a fundamental role in understanding the landsliding mechanism. Where landslide processes are the main modelling agents, bedding planes of layered formations can control both the landslide mechanism and the activity, in terms of style and distribution (cf. WP/WLI, 1993; Cruden and Varnes, 1996). Therefore, the definition of the lithostructural setting is a basic aspect in landslide susceptibility assessment, as its spatial prediction implies careful evaluation of the geo-structural conditions in areas where both first-time and reactivated events can develop.

The analysis of the relationship between bedding plain attitude and topography can be a key procedure in identifying and comprehending the structural control on slope and landslide evolution. Moreover, the abundance, the frequency and/or distribution and the geomechanical characteristics of the stony component within the sequences, in comparison to the more clayey part, may produce a different morphoevolutive behaviour of slopes.

At present, computer-aided techniques of geological data management permit the implementation of spatial analyses correlating geo-structural and geological-morphological information characterizing investigated slopes.

Published by Copernicus Publications on behalf of the European Geosciences Union. 
For nearly two decades, the necessity to perform geostructural analyses on a large scale has induced some authors to introduce computer-aided methods to the spatial distribution of azimuth data. Some interpolation techniques aimed at obtaining spatially distributed fields of the orientation of geologic fabrics (in this case bedding-slope relationship) have been presented in scientific literature. One of these is the TOBIA-index (TOpographic/Bedding plane Intersection Angle), proposed by Meentemeyer and Moody (2000). Even though this index provides the conformity between slope and bedding planes by means of the computation and the digital mapping of their intersection angle, model outputs are not unique due to the continuous representation. By using the direction cosines (de Kemp, 1998; Günther, 2003) for decomposing irregularly distributed attitude measurements, the interpolation of azimuth data avoids the occurrence of numerical gaps in crossing over Cartesian quadrant boundaries, instead. Nevertheless, the direction cosines method interpolates azimuth measurements in a continuous manner. Therefore, it does not provide for discontinuity thresholds due to sudden and wide azimuth variations in adjacent points. For example, interpolation between two azimuth values at intervals of about $180^{\circ}$ is portrayed rather as an idealized continuous semicone-shaped surface than as a fold, which represents the most frequent natural condition.

This paper describes and presents a new computer-aided methodology, NADIA (Non-continuous Azimuth DIstribution methodological Approach) aimed at producing a both continuous and discontinuous distribution of azimuth data in relation to typical and recurrent geological settings. A set of computational procedures has been developed as well, aimed at slope characterising and modelling in terms of structural control. By means of discrete data processing of geometrical slope parameters and orientation of geological features (bedding planes), simple determinations of slope sectors where structural control plays a key role on the development and evolution of landslide phenomena have been computed.

Furthermore, this study identifies and proposes some Litho-Structural Models (LSMs) of slopes, aiming at recognizing recurrent and specific litho-structural settings which may control landslide evolution. The study area corresponds to an inland sector of the Southern Italian Apennine, mainly characterized by instabilities of the earth flow type (Guadagno et al., 2008).

\section{A very complex geological environment}

The lithological and structural complexity of an area is often one of the main factors characterizing landslide-prone conditions. In mountainous areas, such as the Italian Apennines, the influence of tectonic phases on lithologically complex sequences has produced peculiar settings that represent predisposing causes controlling the spatial evolution of landslides. This background is representative of the morphological evo-

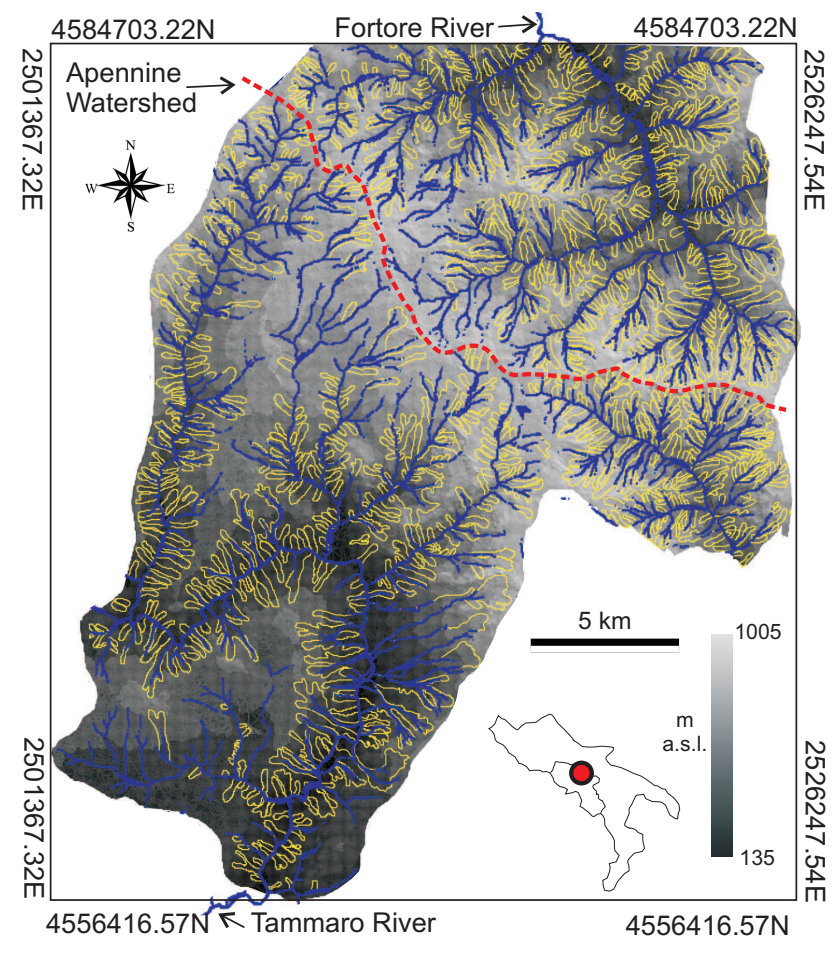

Fig. 1. Location map and DEM of the study area. Landslide distribution (data from Guadagno et al., 2006) is shown in yellow.

lution of slopes in the Benevento province (Southern Italy), where slow-moving landslides are particularly widespread in some areas, giving to the region a distinctive feature. Surveys and multitemporal analyses have shown that most of these instabilities are structurally-controlled or directly connected to the local geological setting both in the source area and along the channel or the accumulation area (Revellino et al., 2010).

The pilot area (about $440 \mathrm{~km}^{2}$ ), belongs to a sector of this province. It includes parts of two catchment basins, selected in order to cover a variety of geological conditions (Fig. 1): (1) the northeastern sector of the Fortore River basin, and (2) the southwestern part of the Tammaro River basin. Concerning the morphological setting, the first one is characterised by a dendritic erosion pattern and the second one by a more complex trend of the drainage pattern, prevalently imposed on tectonic lineaments related to transtensive tectonic phases. Moreover, the data on landslide types and pattern (Guadagno et al., 2006) show that slope instabilities are areally distributed (Fig. 1) and they mainly consist of earth flows with a restricted number of translational, rotational and compound slides. Sometimes translational, rotational or compound movements are only limited to the source areas.

Geologically, the whole of the province (approximately $2000 \mathrm{~km}^{2}$ ) is characterised by the outcropping of sequences at different degrees of lithological and structural complexity. Revellino et al. (2010) grouped these deposits into five successions distinguished by likely lithotechnical homogeneity, 
or more specifically, by similar lithotypes according to their lithology and engineering-geological/geomechanical features. With regards to the area investigated in this paper, two of the five groups of sequences were found; each of them includes more than one lithotechnical unit. They are:

(1) Dominantly pelitic sequences with a high-degree of tectonization. These include (i) clayey-marly sequences, and (ii) fully clayey sequences. Rocks are prevalently incompetent, from mildly to intensely folded; normally clays appear scaly.

(2) Stony and complex successions with a high-degree of tectonization. These consist of (i) calcareous-clayey sequences organized in well stratified strata and banks, and (ii) arenaceous-clayey and arenaceous-conglomeratic sequences consisting of mainly arenaceous and conglomeratic banks and subordinate thin layers of marls, clays and conglomerates. Both sequences are intensely jointed and folded.

The structural setting of the area is rather complex due to thrust-belt structures of carbonate and silico-calcareoclastic terrains and wedge top/piggy-back basin successions. The regional structure of the Chain is the result of some main tectonic phases (D’Argenio et al., 1973; Patacca and Scandone, 2001): (i) older compressive phases, which produced multiple trusts associated to anticlines and synclines complex systems, and (ii) more recent extensional phases with prevailing normal and strike-slip faulting and persistent and diffused jointing.

During compressive phases, flysch sequences generally showed a differentiated response to deformation. The relative abundance of stony layers favoured a prevalently fragile behaviour resulting in jointing at different scales. As the clayey component increased, deformation occurred without loss of continuity at basin scale. Therefore, the stony layers are characterized by a dense fissure pattern and, where the clay and shale component abounds, this latter has resulted in parasitic minor folding and scaly structures.

\section{Methods of analysis and processing}

Two spatial distribution indexes, $\Delta$ and $C$, have been computed to define the bedding-slope relationship and recognize the stony component of the sequences, which operates an evolutive control of landslide masses, respectively. Since the orientation of a geologic fabric is well defined by the dip and the dip direction, $\Delta$ and $C$ calculation requires the estimation of the following variables: (i) slope aspect or exposure $\left(\psi_{S}\right.$; $\left.0-360^{\circ}\right)$; (ii) azimuth of bedding plane $\left(\psi_{L} ; 0-360^{\circ}\right)$; (iii) slope angle $\left(\alpha ; 0-90^{\circ}\right)$; (iv) dip angle $\left(\beta ; 0-90^{\circ}\right)$.

It should be noted that the spatial distribution of azimuth, which represents a point data, becomes a major aspect in calculating $\Delta$ and $C$. This distribution should suit the spatial variability of azimuth measurements, which is typically observed in geologically complex environments. In most cases, the geological complexity and poor and limited out- crops make the full reconstruction of a clear structural framework very difficult. This aspect motivated the development of a continuous/discontinuous (non-continuous) distribution method of azimuth data, NADIA (Non-continuous Azimuth DIstribution methodological Approach).

\subsection{Azimuth data interpolation (NADIA)}

Angular data processing through GIS tools cannot be undertaken directly using standard techniques for the spatial distribution of data. This is due to the fact that a circular domain is associated to these variables. Therefore, interpolation techniques of the "one-way" type cannot be used. In addition, in most cases, actual settings due to tectonic effects show a continuous spatial trend for narrow angle ranges only (layer distortion); in contrast, the spatial trend acquires a discontinuous character for wide angular ranges.

With the aim of avoiding the described approximation, a methodological procedure, NADIA, has been implemented, which joins matrix operations (GRID) of angular and trigonometric data in Boolean algebra to standard techniques of spatial interpolation. Data processing and the spatial distribution of variables have been performed by means of ArcView GIS Platform (ESRI, 1999) implemented with Spatial Analyst and Grid tool extensions and 3-D Analyst modules. Moreover, all angles in degrees (azimuth and dip) have been converted in radian.

NADIA is founded on the periodicity and, therefore, on the continuity shown by the sine and cosine trigonometric functions in the circular domain. Angle values turned into sine and cosine can be interpolated in a continuous and twoway manner. For this purpose and in contrast to stochastic techniques, the application of IDW (Inverse Distance Weighting) deterministic interpolation methodology (Davis, 1986) guarantees that the spatial distribution of the trigonometric variables is defined in the finite domain [ -1 to 1$]$. Moreover, IDW applied to trigonometric values permits the following advantages (Fig. 2): (i) if interpolation occurs in a narrow range of values, the trend of interpolated data fits the sine and cosine function trend (conditions $\mathrm{A}$ and $\mathrm{B}$ in Fig. 2); (ii) if interpolation occurs in long angular arcs, the trend of interpolated data intersects the sine and cosine function (condition $C$ in Fig. 2). This implies that spatially distributed trigonometric data is continuous for narrow angle ranges and discontinuous for wide angular ranges (right side of Fig. 2). Additionally, as two angular values are respectively associated to sine and cosine in different Cartesian quadrants of the $0-2 \pi$ domain, their independent interpolation enables the production of unique outputs, making it possible for azimuth values to fall into the right quadrant. Once the quadrant is identified, the final value results from the arithmetic mean of angles produced by the inverse trigonometric function sine and cosine.

Therefore, in order to spatially distribute $\psi_{L}$, the first step consists in a spatial interpolation of $\sin \psi_{L}$ and $\cos \psi_{L}$ by 

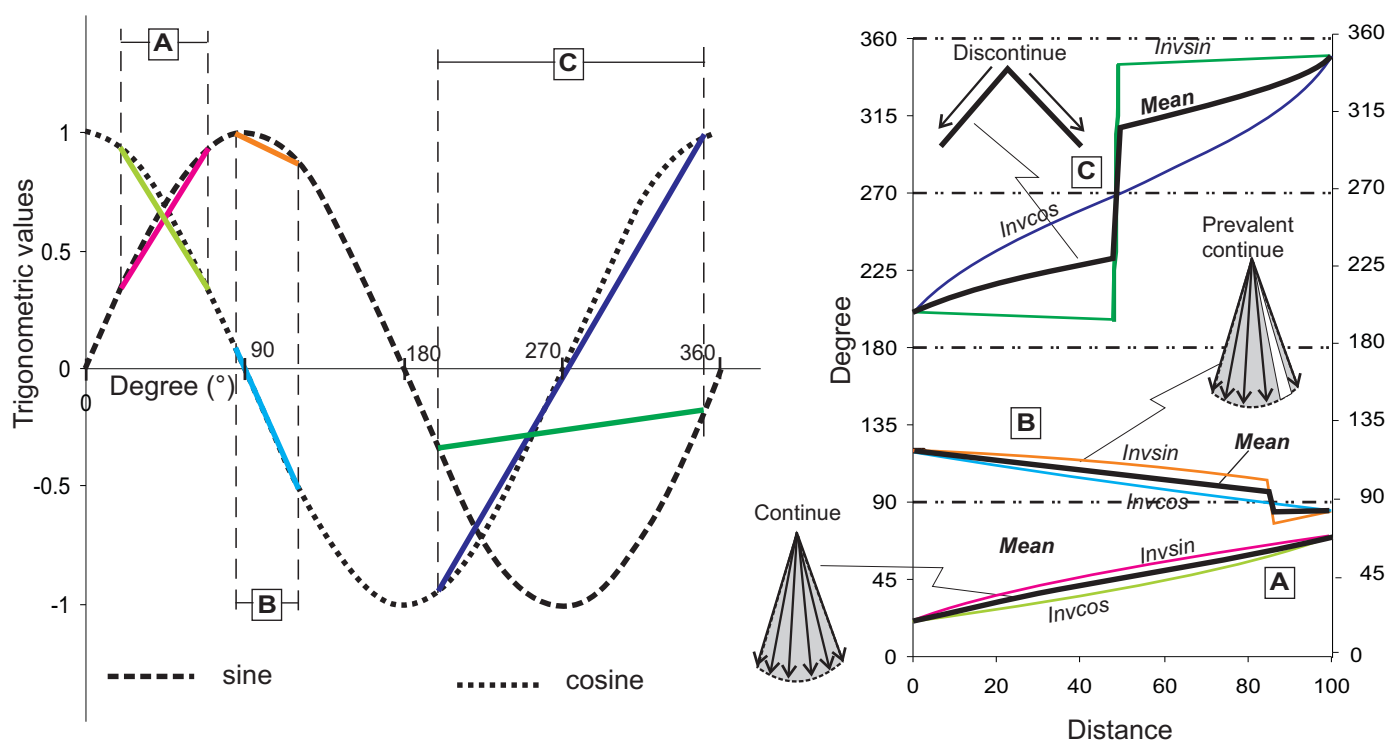

Fig. 2. Linear interpolation of sine and cosine (left side) and their angular distribution by applying IDW (right side; Davis, 1986) in different simulated conditions: (A) short arcs within the quadrant; (B) short arcs across quadrant boundary; (C) long arcs across quadrant boundary.

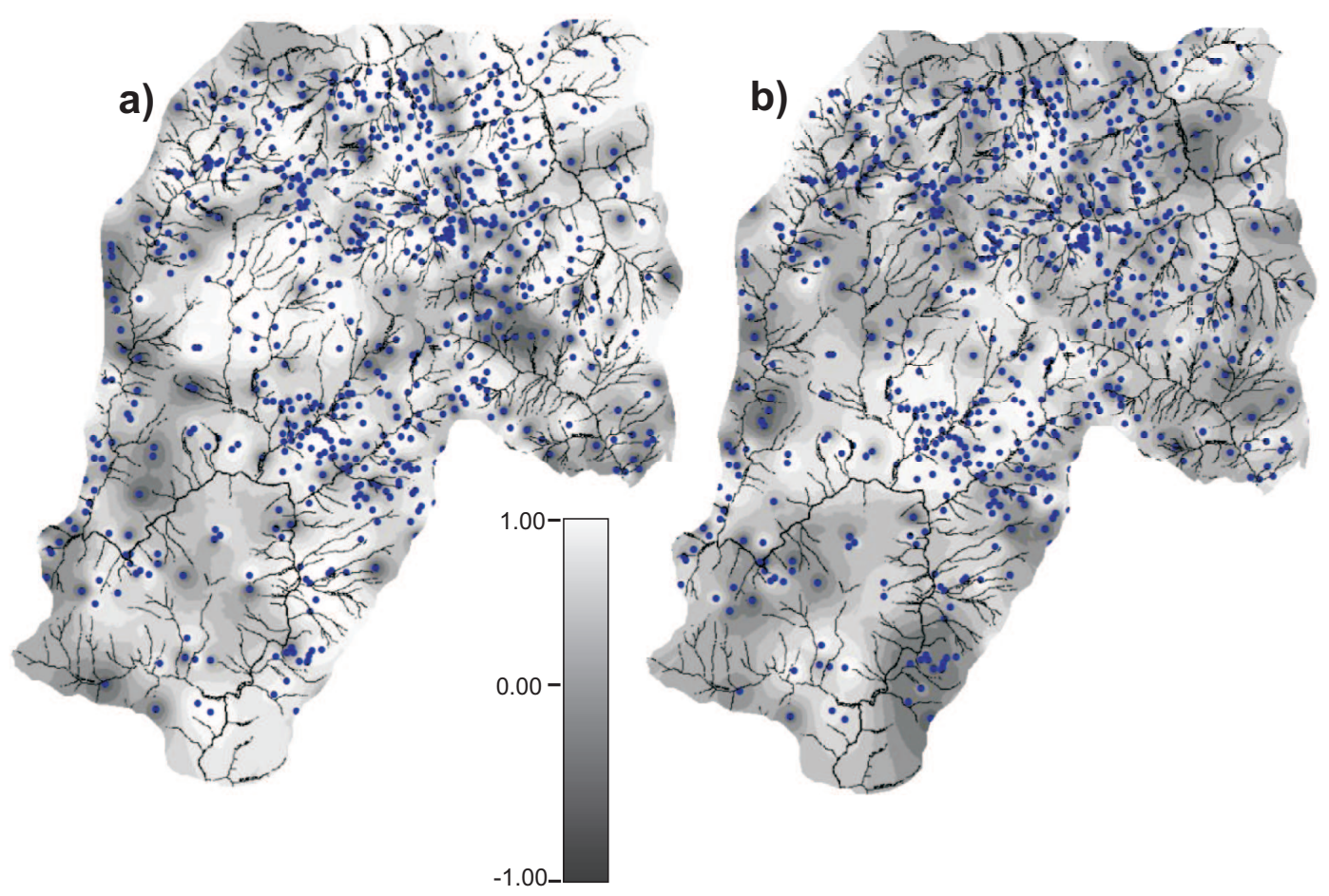

Fig. 3. Spatial distribution of $\sin \psi_{L}$ (a) and $\cos \psi_{L}$ (b) by IDW technique. Azimuth point measurements are shown by blue spots.

means of the IDW technique (Fig. 3). For the present study, we used 633 azimuth measurements collected from field surveys and from 1:25000 to 1:100000 scale official geological maps (Servizio Geologico d'Italia, 1971; Pescatore et al., 2008; ISPRA, 2011).
As stated above, after obtaining the grids, the conversion into angular values was done according to the character that they assume in the four Cartesian quadrants (Fig. 4). More specifically: 


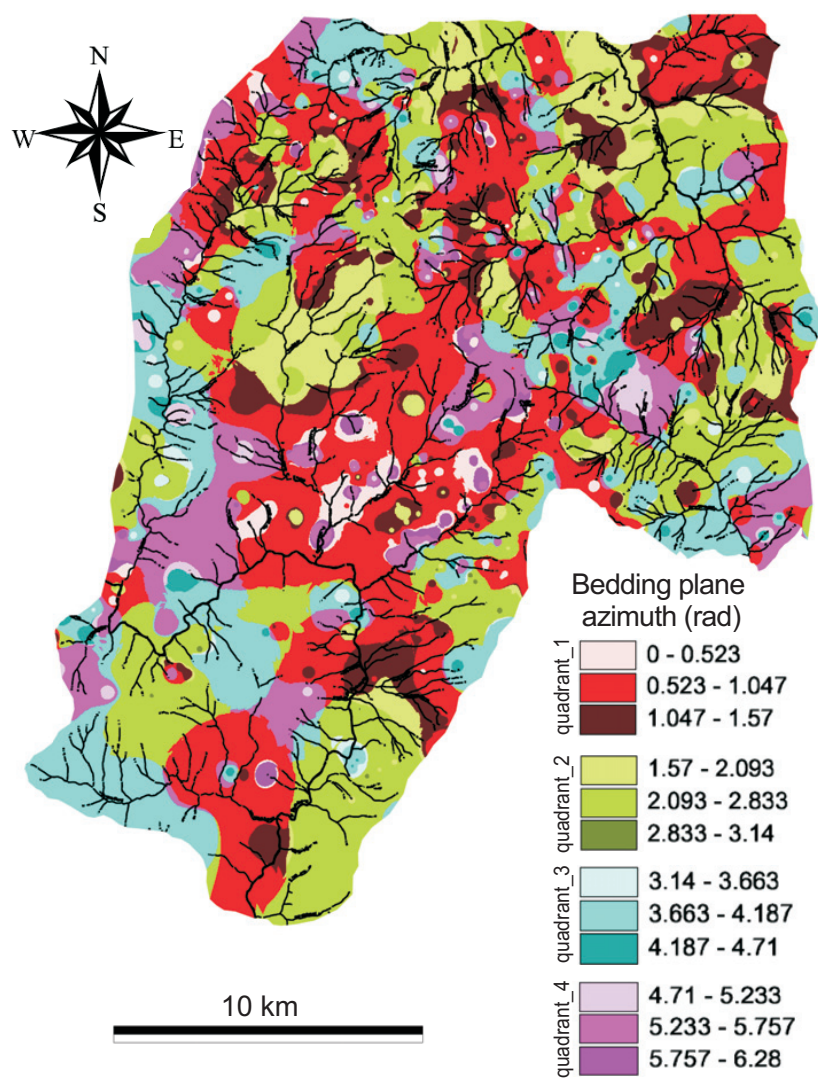

Fig. 4. Spatial distribution of bedding plane azimuths $\left(\psi_{L}\right)$ by NADIA.

[quadrant_1] $=\left(\left(\left[\sin \psi_{L}\right]>0\right)\right.$ and $\left(\left[\cos \psi_{L}\right]>0\right) \cdot\left(\left[\sin \psi_{L}\right]\right.$ .ASin $\left.+\left[\cos \psi_{L}\right] . A \operatorname{Cos}\right) / 2$;

[quadrant_2] $=\left(\left(\left[\sin \psi_{L}\right]>0\right)\right.$ and $\left(\left[\cos \psi_{L}\right]<0\right)$

$\cdot\left(\pi-\left[\sin \psi_{L}\right] \cdot A \operatorname{Sin}+\left[\cos \psi_{L}\right] \cdot A \operatorname{Cos}\right) / 2 ;$

[quadrant_3] $=\left(\left(\left[\sin \psi_{L}\right]<0\right)\right.$ and $\left(\left[\cos \psi_{L}\right]<0\right)$

$\cdot\left(\pi-\left[\sin \psi_{L}\right] . A \operatorname{Sin}+2 \pi-\left(\left[\cos \psi_{L}\right] \cdot A \operatorname{Cos}\right) / 2\right.$;

[quadrant_4] $=\left(\left(\left[\sin \psi_{L}\right]<0\right)\right.$ and $\left(\left[\cos \psi_{L}\right]>0\right)$

- $\left(2 \pi+\left(\left[\sin \psi_{L}\right] . A \operatorname{Sin}+2 \pi-\left(\left[\cos \psi_{L}\right] . A \operatorname{Cos}\right) / 2\right.\right.$; consequently:

$\left[\psi_{L}\right]=\sum_{n=1}^{4}$ [quadrant_n]

where .ASin and .ACos correspond to $\sin ^{-1}$ and $\cos ^{-1}$, respectively and all the map calculator functions are reported in italic.

Figure 5 shows some examples of linear interpolation between two points which are at a distance of 100 units of measurement by using the methodology described above. As it is possible to observe, the azimuth distribution is continuous for angle ranges not exceeding $40^{\circ}-60^{\circ}$; in contrast, wider ranges result in a discontinuous distribution, as occurs when folds and angular unconformity are present. However, it should be noted that the linear interpolation process of sine and cosine variables produces different distributions regardless of the bound value of the considered ranges. In particular, (i) in discontinuous distributions, few intermediate anomalous angular values can be exhibited (Fig. 5c), (ii) a discontinuous pattern is shown by narrow angle ranges across adjacent quadrants (Fig. 5d). In Fig. 6 an example is given of the spatial representation of the azimuth distribution of a hypothetical anticline fold.

\subsection{The $\Delta$-index}

The bedding-slope relationship can be locally defined by the $\Delta$-index, which can be expressed by the following relationship:

$\Delta=0.5-\left(\left|\psi_{S}-\psi_{L}\right| / \pi\right)$

having the physical condition that $\left|\psi_{S}-\psi_{L}\right| \leq \pi$.

The $\Delta$-index, which assumes values in the finite domain [ -0.5 to 0.5$]$, describes the structural setting of three types of slopes (Fig. 7) as categorized by Powell (1875): (a) cataclinal slope, if bedding planes dip in the same direction as the slope; (b) orthoclinal slope, if the azimuth of the dip direction is orthogonal to the azimuth of the slope direction, and (c) anaclinal slope, if bedding planes dip in the direction opposite to the slope. Furthermore, the continuous character of $\Delta$ also defines intermediate slope orientations, plagioclinal slope (Callaway, 1879), which is useful for describing the remaining slopes oblique to the strike of the bedding.

The spatial distribution of $\psi_{s}$ (Fig. 8) is derived from highresolution Digital Elevation Model (DEM)-data (5 m); $\psi_{L}$, on the other hand, can only be obtained by field measurements. This contains the limitation that measurements are restricted where bedding layers outcrop; therefore, $\psi_{L}$ assumes a "point-to-point" character. In addition, both for its physical (angle) and geological (azimuth) nature, the spatial interpolation of $\psi_{L}$ must take into account the following conditions: (i) existence limited to the finite domain $[0 ; 2 \pi]$, (ii) behaviour depending on the direction (zeroing to the north), and (iii) discontinuous distribution due to the presence, for example, of folds or angular unconformities.

As stated above, the $\Delta$-index (Eq. 1) is the result of a matrix operation aimed at defining the orientation of geologic fabrics in relation to the slope aspect. In order to guarantee that the function conforms to the directional requirement or it is always valid in the condition $\left|\psi_{S}-\psi_{L}\right| \leq$ $\pi \mathrm{sg}$ the following methodological process has been adopted:

$[\mathrm{Map} 1]=\left(\left[\psi_{s}\right]-\left[\psi_{L}\right]\right) . A b s$

$[\mathrm{Map} 2]=\operatorname{not}([\mathrm{Map} 1] \geq \pi) \cdot[\mathrm{Map} 1]$; 

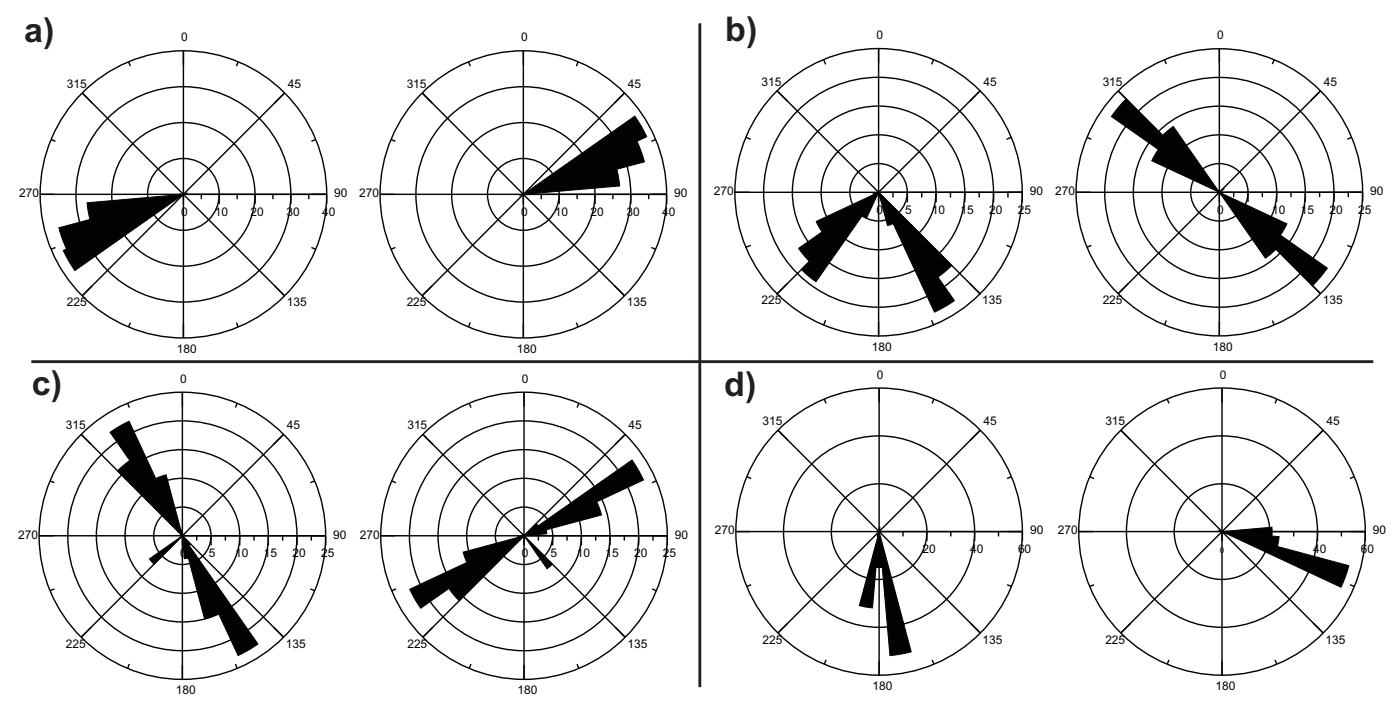

Fig. 5. Linear interpolation between two azimuth values which are at a distance of 100 unities of measurement: (a) continuous distribution, (b) discontinuous distribution, (c) non-uniform discontinuous distribution, and (d) non-uniform continuous distribution.

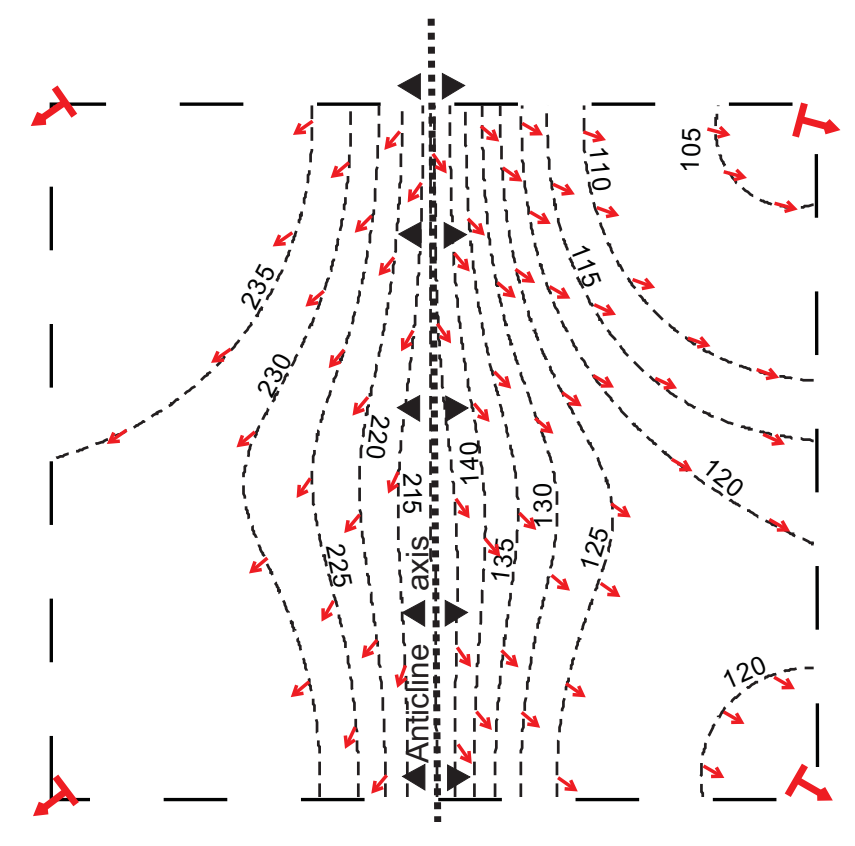

Fig. 6. Spatially-distributed estimates of an anticline with axis strike oriented north-south. For distribution of sine and cosine, the IDW technique is applied with a power of four.

$[$ Map3 $]=\operatorname{not}([\mathrm{Map} 1]<\pi) \cdot[2 \pi-$ Map1 $]$; and consequently,

$$
[\Delta]=0.5-(([\text { Map } 1]+[\text { Map2 }]) / 2 \pi)
$$

Figure 9 shows the $\Delta$ distribution in the study area, where chromatic variations refer to $\pm 20^{\circ}$ range around the pure orientation of cataclinal slopes, anaclinal slopes and orthoclinal slopes as conventionally categorized by Cruden and
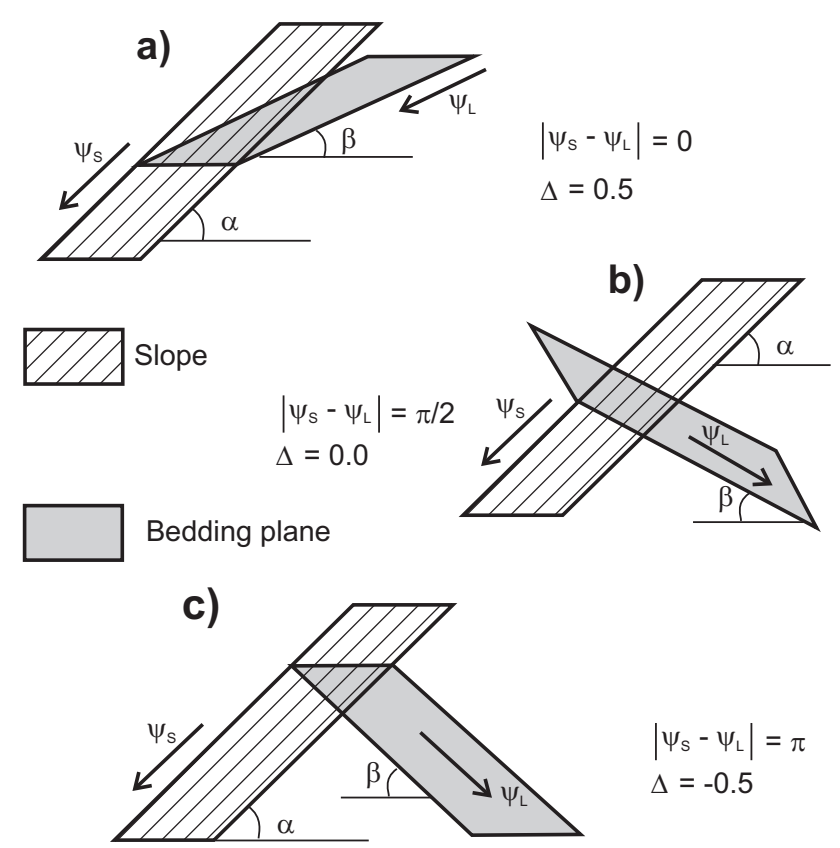

Fig. 7. Bedding-slope relationships defined by $\Delta$ for: (a) cataclinal slope, (b) orthoclinal slope, and (c) anaclinal slope.

$\mathrm{Hu}$ (1996). The absolute spatial distribution of the three topographic/bedding orientations highlights the situation that anaclinal slopes prevail over the others, while cataclinal slopes are less diffused. In addition, comparing the ratio between slope surfaces involved in landsliding and total slope area with $\Delta$, a concordant trend has been plotted showing anaclinal and orthoclinal slopes as the most affected by instabilities (Fig. 9b). With regards to topographic slopes, the 


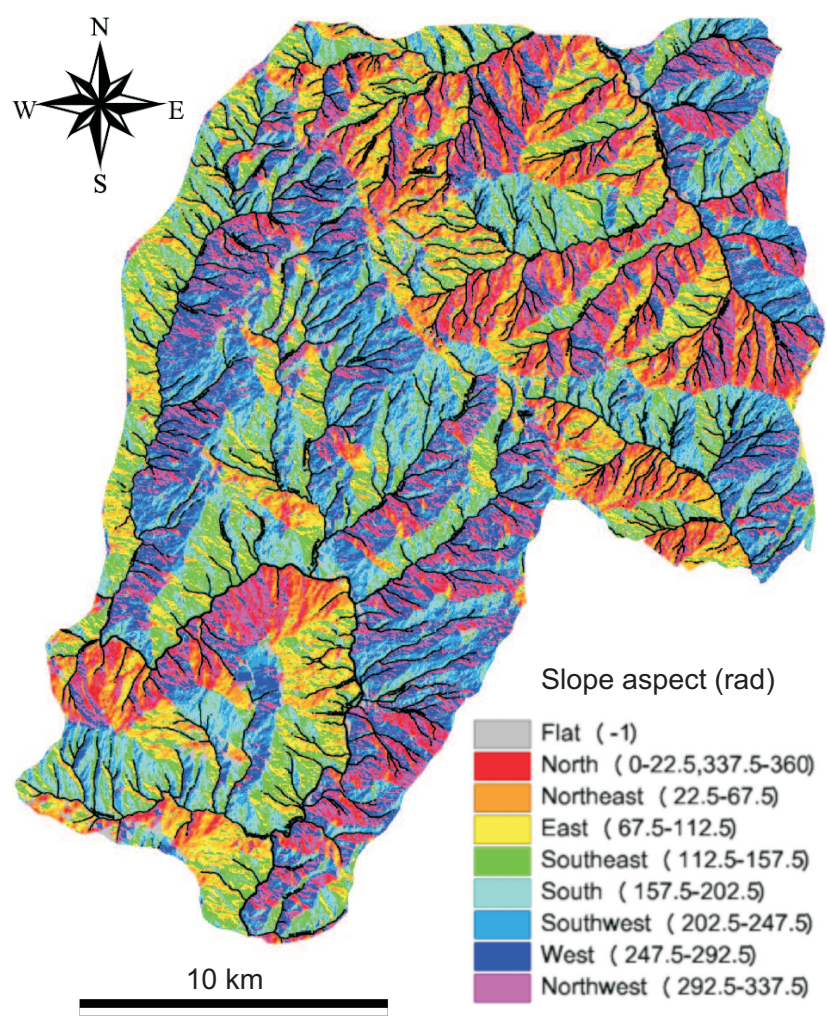

Fig. 8. Slope aspect $\left(\psi_{S}\right)$ derived from high resolution DEM from a 1:5000 scale topographic map $(5 \mathrm{~m})$.

relationship between slope angle and slope area for anaclinal and cataclinal slopes shows similar patterns with maximum values of approximately $11^{\circ}$ (Fig. 9c).

\subsection{The structural control $C$-index}

The stony component within structurally complex formations is often one of the key factors linked to the structural control of landslide bodies. In order to recognise this effect in cataclinal and anaclinal slopes only, the following control index $(C)$ has been defined (Fig. 10a):

$C=\Delta \operatorname{tag}|\alpha-\lambda|=0.5-\left(\left|\psi_{S}-\psi_{L}\right| / \pi\right) \operatorname{tag}|\alpha-\lambda|$

where $\lambda$ is a variable depending on the areal distribution of $\alpha$ in the study area. In particular it is expressed as:

$\lambda=\alpha_{\max *}-\pi / 4$

where $\alpha_{\max *}$ defines the maximum attributed value of $\alpha$. As shown in Fig. 10b, this value is associated with the point that exhibits a sudden and significant change of inclination in the cumulative spatial distribution of $\alpha \mathrm{u}$ In this study, $\alpha_{\max } *$ refers to $99 \%$ of the area and corresponds to an angle of $38^{\circ}$.

With regards to the structural control of rocky layers on the evolution of landslides, this control can be recognized by means of specific slope angles connected to the slope classes previously described. Therefore, two finite intervals in the existence domain of $C$ have been fixed in relation to specified slope angles. In particular, these conditions are identified by the bi-logarithmic distribution curve of slope angles (Fig. 10c). This distribution shows a quick decrement after reaching the peak value ( $\left.\alpha_{\text {peak }}\right)$ at an angle of $10^{\circ}$, which can be compared to the residual shear strength of some typical clays of the area (Grelle and Guadagno, 2010). The bisector of the angle obtained by the intersection of the linear part extension and of the tangent to the peak intercepts the distribution curve in the value named $\alpha^{*}$. This latter then aims at identifying the lower threshold defining slope angles influenced by the outcrop of stony sequences. In other words, it is assumed that slopes having a slope angle higher than $\alpha^{*}$ correspond to sectors where stony layers are outcropping. For the study area, $\alpha^{*}$ has been found to be equal to $17^{\circ}$. In particular, it is possible to highlight that, in similar slope areas characterized by $\alpha_{\text {peak }}$ close to $10^{\circ}, \alpha^{*}$ falls into the $10-20^{\circ}$ range, where the log-diagram has a higher resolution.

\section{Litho-Structural Models}

Because of the litho-structural features investigated, $\Delta$ and $C$ quantitative indexes were qualitatively related and compared with some simple Litho-Structural Models (LSMs) of the slope. LSMs aim at depicting and schematizing the most recurring litho-structural settings of entire slopes or of slope sectors in the study area in order to elaborate evolutive models controlling landslide scenarios. Correlation between $\Delta$ and $C$ indexes and LSMs is justified by the fact that, even though areally distributed, these indexes include information regarding the slope attitude (internal geometry). LSMs not only consider the relationship slope/bedding (in particular cataclinal and anaclinal slopes) by means of $\Delta$ but also the presence, the relative abundance and the position (top or bottom) of stony layers within sequences by using $C$.

In the LSMs, the various sequences do not take into consideration the depositional relationship among the different lithological units and the nature of their contacts (sedimentary or tectonic). Consequently, three main types of tectonicstratigraphical sequences can be defined within the LSMs: (i) clayey sequence dominant at the top (TC), (ii) clayey sequence dominant at the bottom (BC), and iii) indistinct clayey sequence (IC). TC and $\mathrm{BC}$ sequences relate to the field defined in Fig. 10c. The following most frequent LSMs will be proposed and discussed in the next Paragraphs: (1) LSMs related to cataclinal slopes; (2) LSMs related to anaclinal slopes; (3) LSMs related to IC; (4) LSMs related to complex settings.

It should be noted that, in areas involved in well-known landslides, the recognition of slope sectors ascribable to LSMs, supported by $\Delta$ and $C$ too, may help to identify similar scenarios where bedding control on landslides occurs both in terms of predisposing causes (and/or increased landsliding) and of the spatial constraint of evolution. 

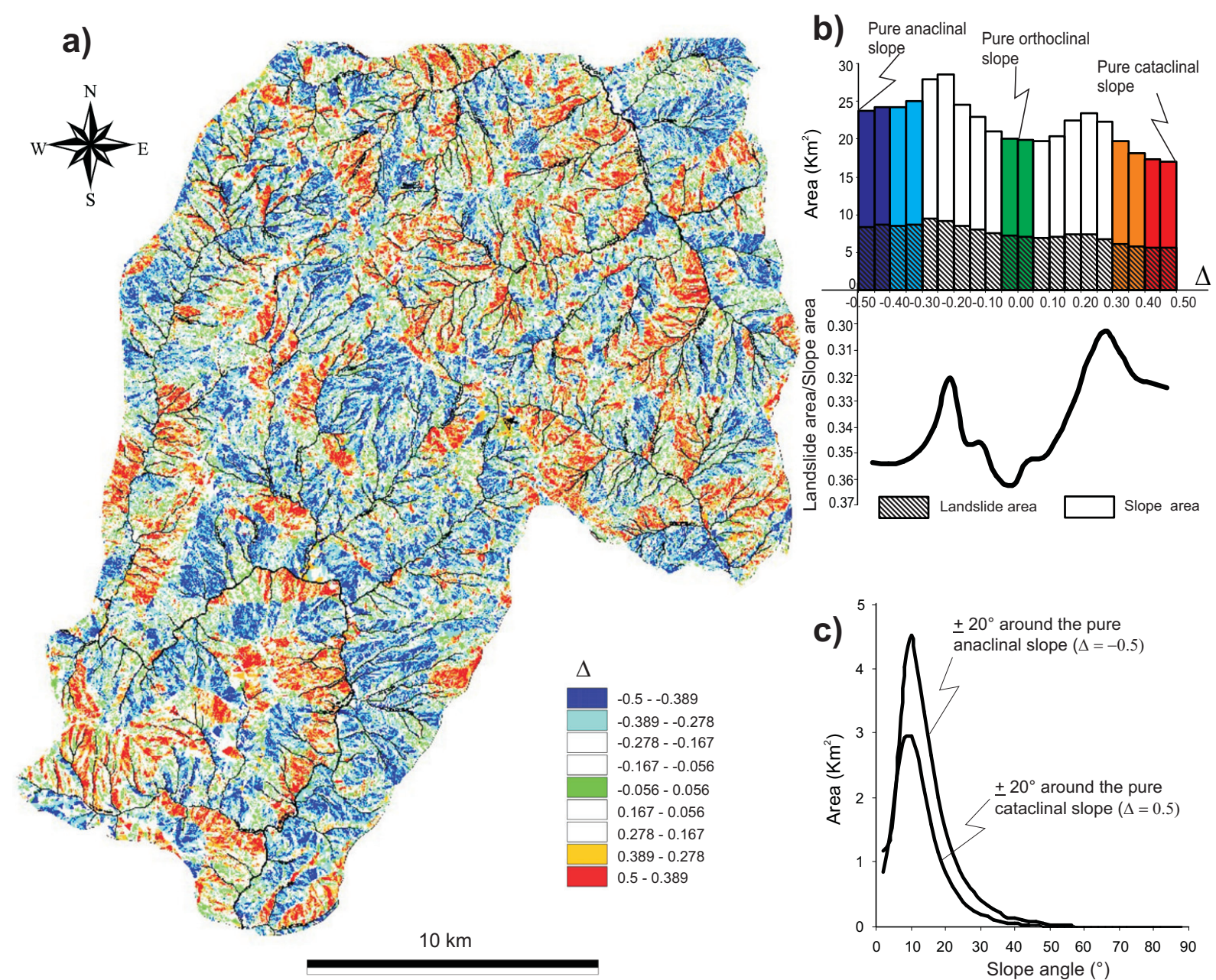

Fig. 9. (a) Grid map of $\Delta$-index; (b) Spatial distribution of $\Delta$ related to the total slope area and the landslide area; (c) Slope angle versus slope area for anaclinal and cataclinal slopes

\subsection{LSMs related to cataclinal slopes}

Cataclinal slopes are usually well-known as the most landslide-prone environments. Due to the fact that for this slope type, dip angles may represent the predisposing key factor, LSMs were developed taking into account additional slope categorizations as suggested by Cruden and $\mathrm{Hu}$ (1996). Therefore, cataclinal slopes were further divided based on the geometric relationship between the dip of the bedding planes and the slope angle into: (i) overdip slopes, which are steeper than the dip of the bedding plane, (ii) underdip slopes, which are less steep than the dip of the bedding plane, and (iii) dip slopes, which follow the bedding plane.

Overdip slopes $(\alpha>\beta)$ with a TC sequence represent one of the most frequent conditions of structural control in the area (Fig. 11a). In this case, the rocky or rocky-clayey member at the bottom induces a better exposition of the clayey member at the top against actions concurring with landsliding. This setting also creates a different morphology be- tween the landslide source area set upslope and the channel at middleslope, the latter being more steep. This form also influences landslide mobility since a larger amount of potential energy is given to the masses, resulting in a more rapid disposal of landslide debris downslope. Usually, the retrogressive expansion of landslide source areas takes place rapidly. In contrast, overdip slopes with a $\mathrm{BC}$ sequence (Fig. 11b) show a strong structural control in the landslide source area, where the main scarp is steep and irregular. Here, rock slides of prismatic blocks frequently occur, feeding the clayey visco-plastic mass movement downslope. Retrogressive evolution of the landslide body is slow and differentiated as well as being influenced by the jointing state of the stony component.

In underdip slopes $(\alpha<\beta)$ with a BC sequence (Fig. 11c), retrogressive phenomena are prevented considerably by the dip slope forming upslope, which is steeper than the landslide body. From a morphological point of view, the landslide main scarp takes an almost linear pattern (Fig. 12a). Instead, 


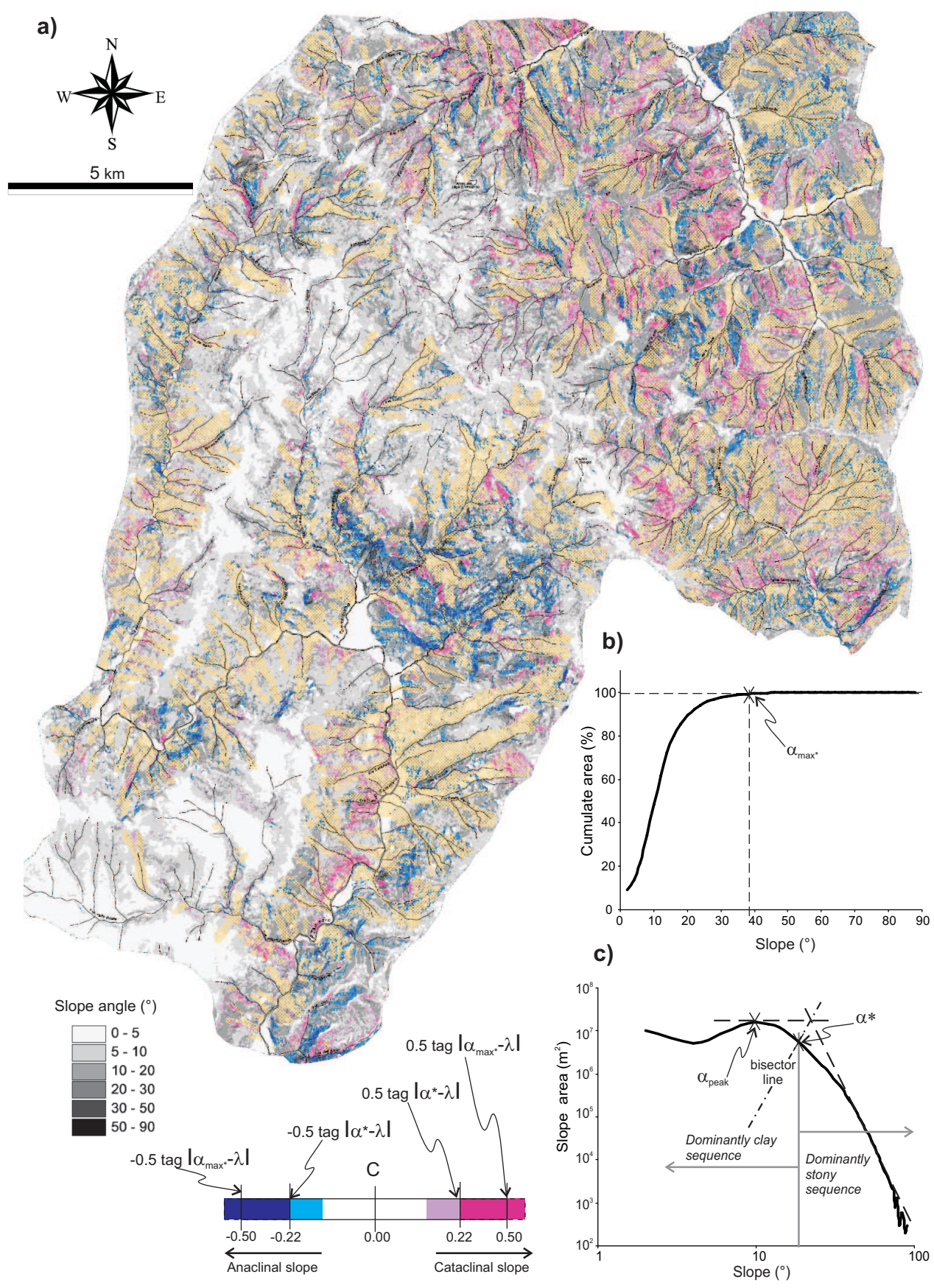

Fig. 10. (a) Spatial distribution of the structural control index $(C)$ related to slope angle and landslide distribution (in yellow); (b) and (c) distribution curves for defining parameters related to Eqs. (2) and (3) and to $C$ field action. In the study area: $\alpha_{\max } *=\alpha_{(99 \%)}=38^{\circ}, \alpha_{\text {peak }}=$ $10^{\circ}$ and $\alpha^{*}=17^{\circ}$.

a TC-BC-TC multilayered condition is displayed in Fig. 12b, where the spatial distribution of $C$ highlights how the prevailing rocky layers influence the evolution of a landslide system characterized by multiple and superimposed source areas.

The form $\alpha \sim \beta$ generally defines the pure dip slope orientation (Fig. 11d). These slopes approach a monoclinal setting with slope angles near the residual friction angle of the clayey component. This structural setting, which cannot be ascribed to tectonics only, may be the result of the mechanical degradation of the former slope by means of translational slides. Active landslides generally appear as single, shallow, and with a smooth boundary. This setting facilitates the superficial water streaming, increasing material erosion and transport downslope. In such a case, the evolved types show lateral secondary landslides creating a multi-source system (Revellino et al., 2010). 


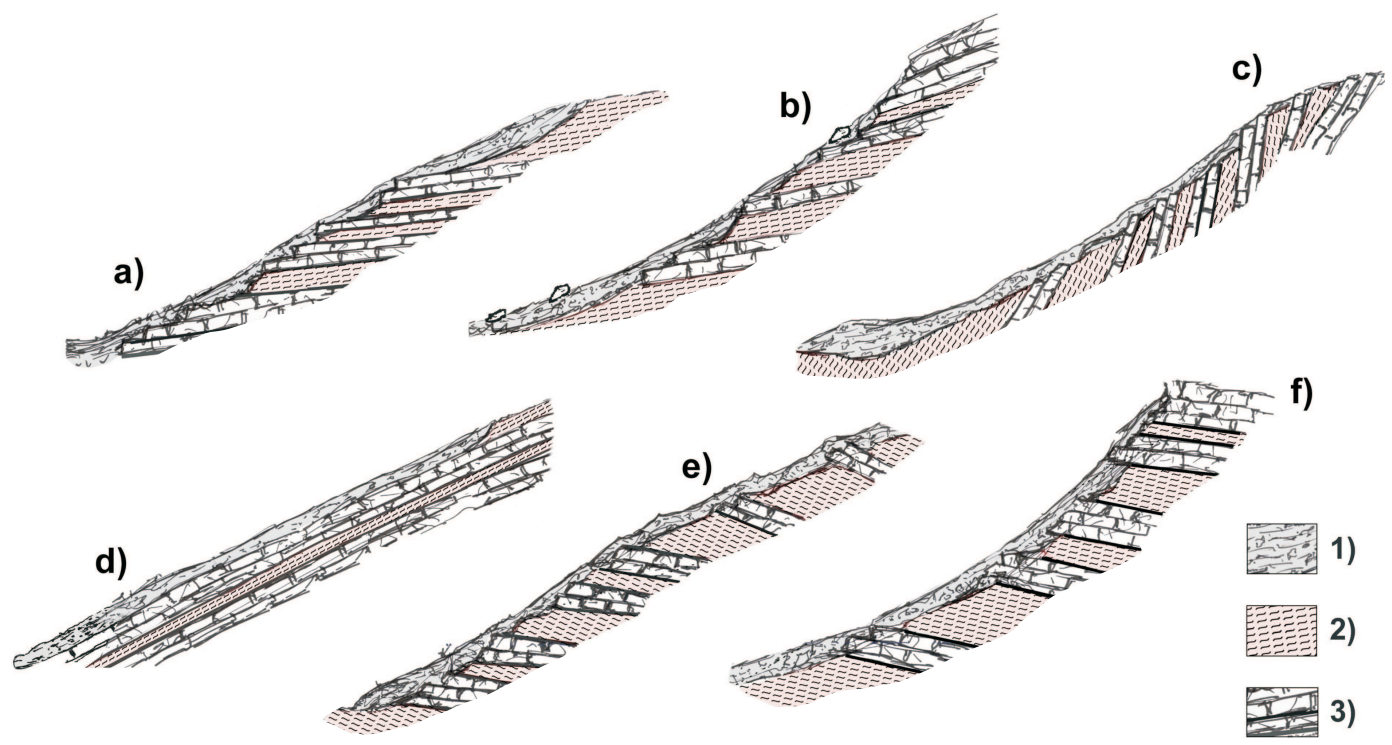

Fig. 11. Basic recurrent LSMs in TC (clayey sequence prevailing at the top) and BC (clayey sequence prevailing at the bottom) sequences: TC (a) and BC (b) related to overdip slopes $(\alpha>\beta)$; BC (c) linked to underdip slopes $(\alpha<\beta)$; pure dip slopes (d) with $\alpha \sim \beta$; TC (e) and $\mathrm{BC}$ (f) related to anaclinal slopes. Legend: (1) landslide body; (2) clayey level; (3) stony level.
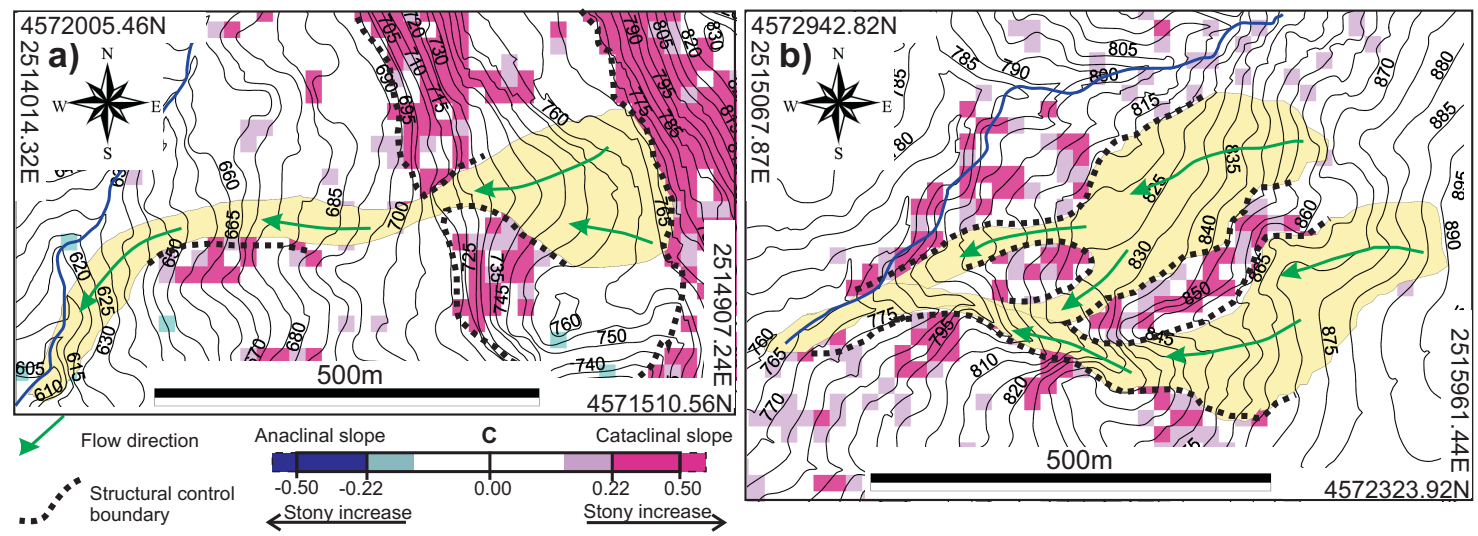

Fig. 12. Structural control on landslides (in yellow) linked to: (a) BC sequence and underdip slopes $(\alpha<\beta)$; (b) TC-BC-TC multilayered sequence and overdip slopes $(\alpha>\beta)$. $C$-index scale is also shown.

\subsection{LSMs related to anaclinal slopes}

The structural setting is characterised by bedding dipping into the slope. In this case, sliding surfaces, since they do not correspond to bedding planes, are more irregular and mainly influenced by the fracturing condition of the masses.

Control induced by a TC sequence (Fig. 11e) can be generally compared to that of the same sequence in cataclinal slopes, as stated above. Only some minor differences can be identified principally resulting in a greater influence on the evolutive development of the landslide process. Typical examples of these LSMs are the St. Andrea and Serra delle Forche landslides (Fig. 13). Both of them show a clear slope change between the clayey top and the rocky-clayey bottom. In the case of the St. Andrea landslide, the sliding material suffers a partial constraint and it divides around more competent strata and comes together again further to the northwest (Fig. 13a). Instead, a total control can be observed for the Serra delle Forche landslide. In this case, the presence of a bedding plane of a stony sequence controls the shape, orientation and evolution at the source area, inducing a widening towards the north and the northeast. From the source, the mass movement forms a cross channel-like feature (Fig. 13b). The similar structural control of the two landslide bodies may suggest that the Serra delle Forche event is a more mature form in comparison to the other.

Landslides developing where the geo-structural setting is characterized by a BC sequence (Fig. 11f) show very 

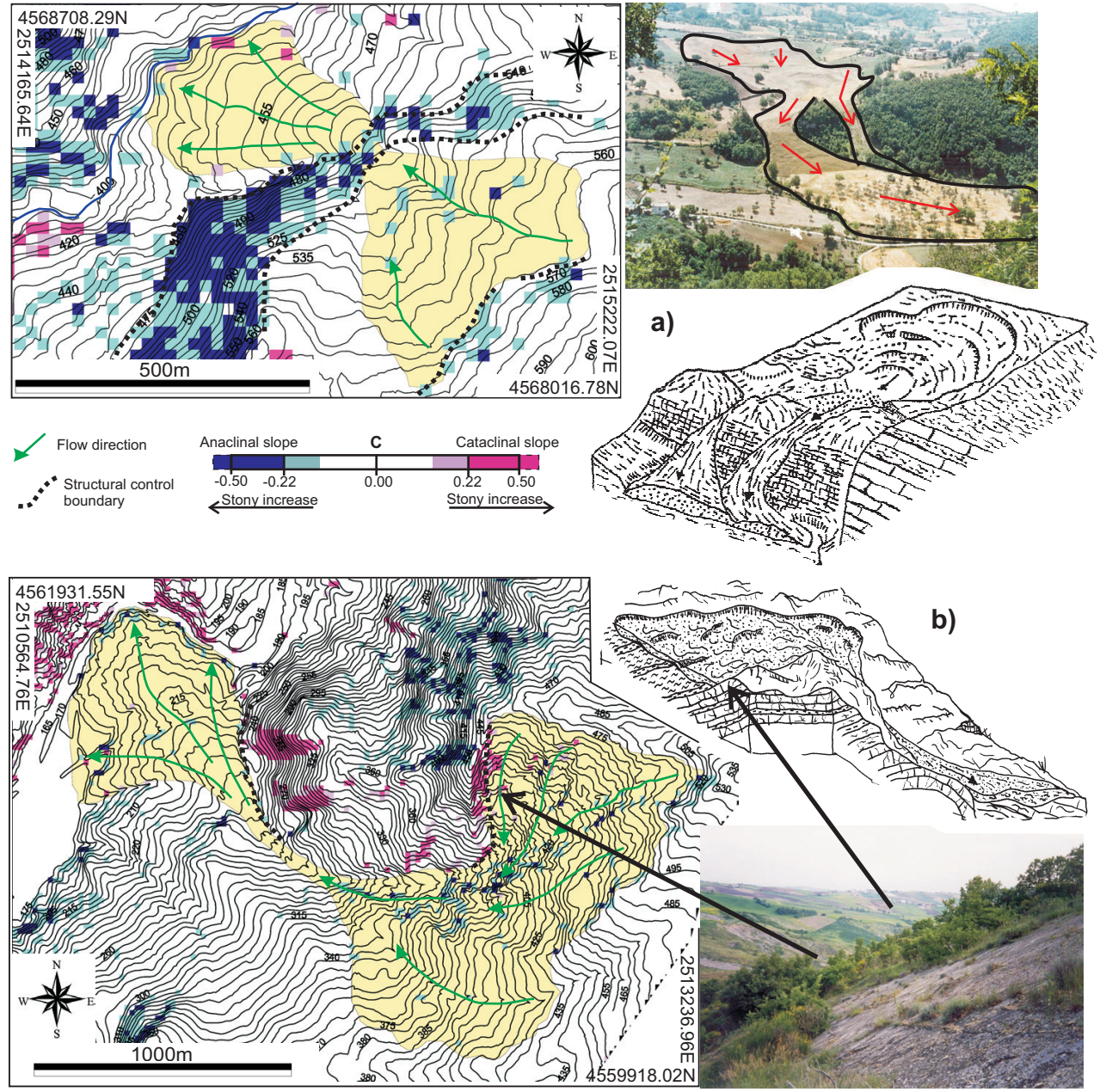

Fig. 13. Structural control on landslides (in yellow) related to TC sequences and anaclinal slopes: (a) landslide map, frontal photograph and schematic representation of the Sant'Andrea landslide; (b) landslide map, photograph and schematic representation of the Serra delle Forche landslide (Photos courtesy of Guido Lupo). $C$-index scale is also shown.

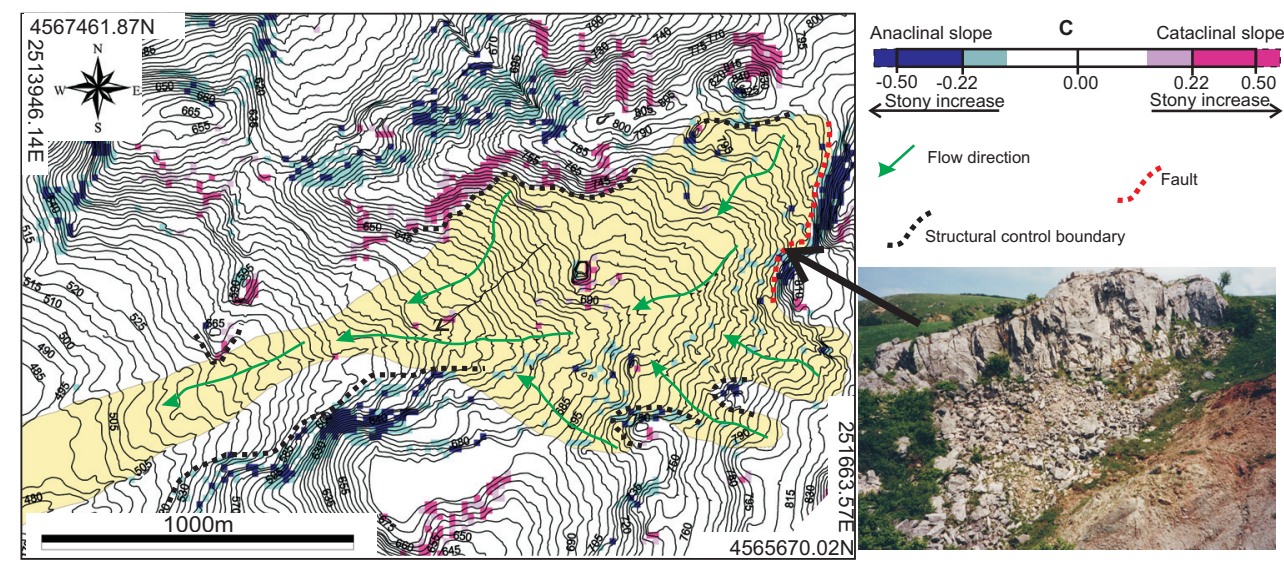

Fig. 14. The Santo Ianne landslide: an example of structural control associated to $B C$ sequence and anaclinal slopes. A portion of the source area is also shown in the picture (Photo courtesy of Guido Lupo). $C$-index scale is also shown. 


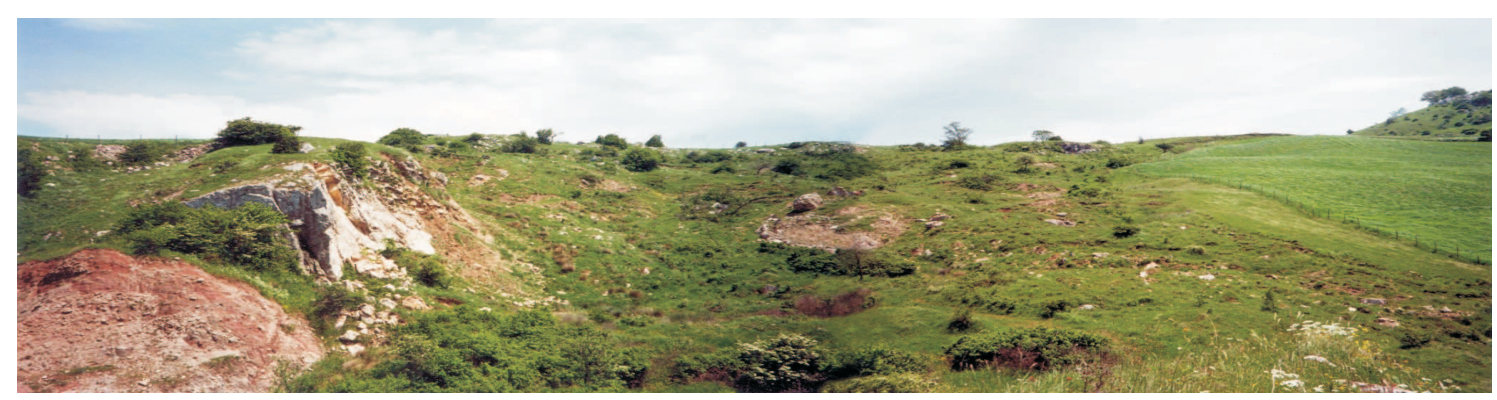

Fig. 15. Rock blocks floating on a landslide body downslope (Photo courtesy of Guido Lupo).

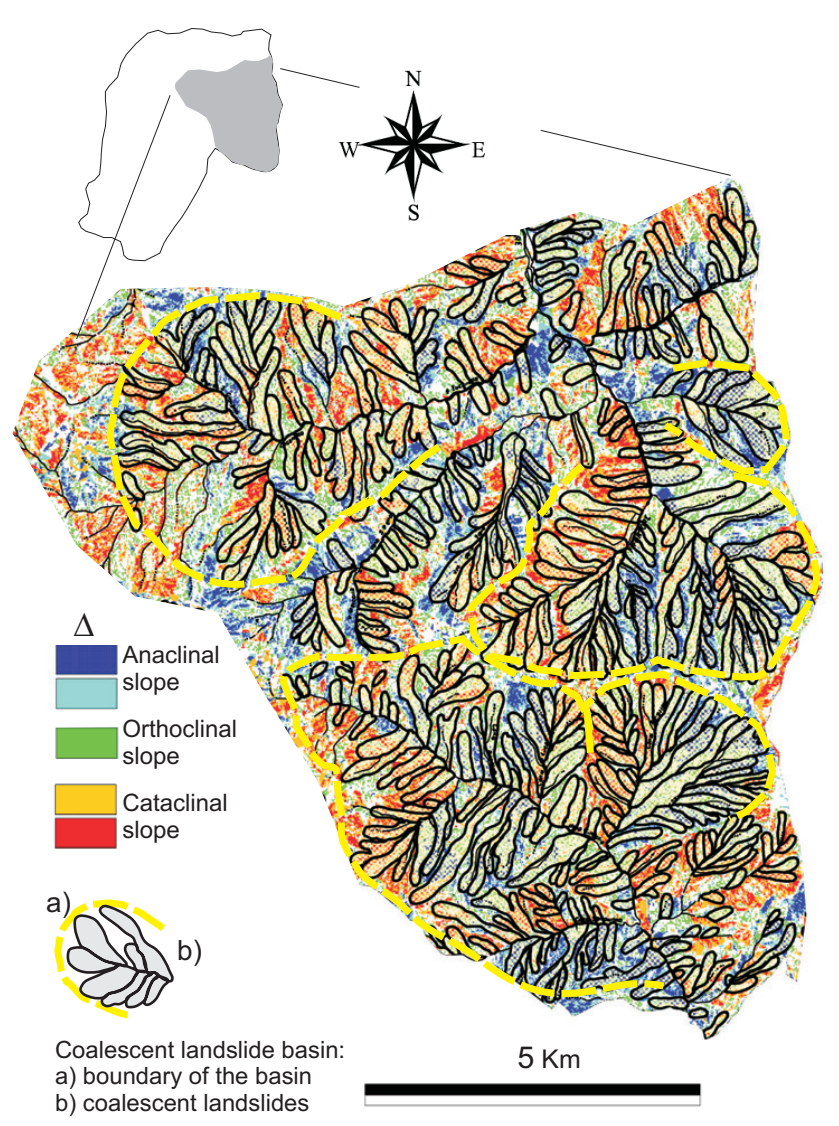

Fig. 16. Coalescent landslides in a sector of the Fortore River related to $\Delta$ distribution.

irregular source areas. This may be principally due to the frequency and persistence of jointing in the stony member (Fig. 14). For large and deep-seated landslides, it is frequent to find prismatic rock blocks of various dimensions floating on the clay mass in visco-plastic movement (Fig. 15).

Finally, the fan-shape morphology of the accumulation zone seems to be a recurrent and a common condition both in $\mathrm{TC}$ and $\mathrm{BC}$ sequences when the structural conditioning causes a narrowing of the channel.

\subsection{LSMs related to IC sequences}

In the presence of IC sequences, it seems that the influence of the bedding plane orientation on landslide evolution is quite poor. Landslide patterns ascribed to coalescent earthflow systems (sensu Revellino et al., 2010), that is, systems formed by several generations of landslides that mobilise and interact, can be found where slopes are constituted of more or less homogeneous clay formations. These groups of landslides can be considered as an entity from a morphological point of view as they occur within a sub-catchment. Values as high as $75 \%$ or more of the Landslide Index (LI), calculated as the percentage of area affected by landslide events per $1 \mathrm{~km}^{2}$ grid, are associated to these sectors (Guadagno et al., 2006). Additionally, systems like these but more evolved originate morphological shapes with associated dendritic drainage patterns.

Figure 16 shows the $\Delta$ distribution, and coalescent landslide systems as well, in a sector of the study area where these geo-morphological conditions can be recognised. The lack or shortage of the stony component within the sequence makes the $C$-index useless to be used.

\subsection{LSMs related to complex settings}

In some cases, spatial distributions of $\Delta$ and $C$ point out complex conditions of structural control, which should be explained by means of a combination of the LSMs described above.

For example, Fig. 17 shows a slope sector affected by a landslide and characterised by the presence of a fold, having the axis perpendicular to the max longitudinal slope direction. An LSM related to this setting can be schematised as a string of LSMs related to anaclinal and cataclinal orientations, from the bottom to the top, as evidenced by the $\Delta$ distribution (Fig. 17a). The landslide source area involves the clayey nucleus of the fold (Fig. 17b) and it is controlled by the outcropping of bedding planes' stony layers at the upper boundary which prevent further retrogressions upslope and at the beginning of the channel, following the $C$ distribution (Fig. 17c). 


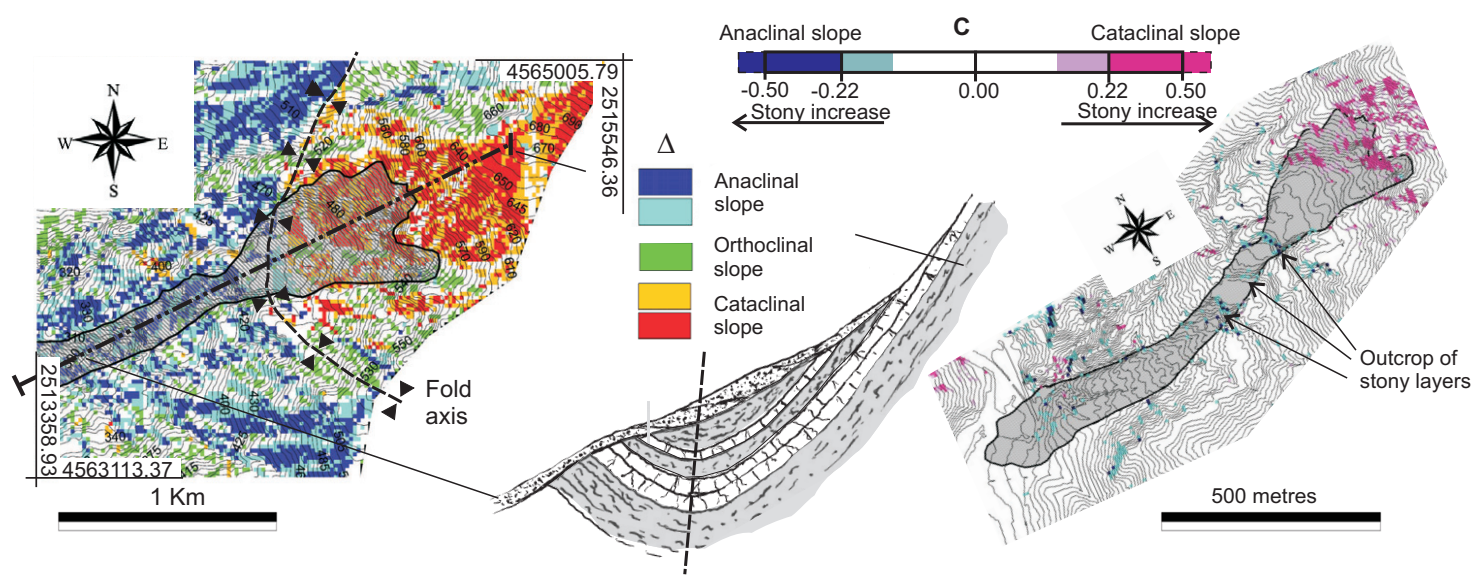

Fig. 17. Landslide occupying the nucleus of a syncline: (a) $\Delta$ distribution in the source area and channel of the landslide; (b) schematic cross-section (1-2); (c) $C$ distribution and evidence of the stony layers.

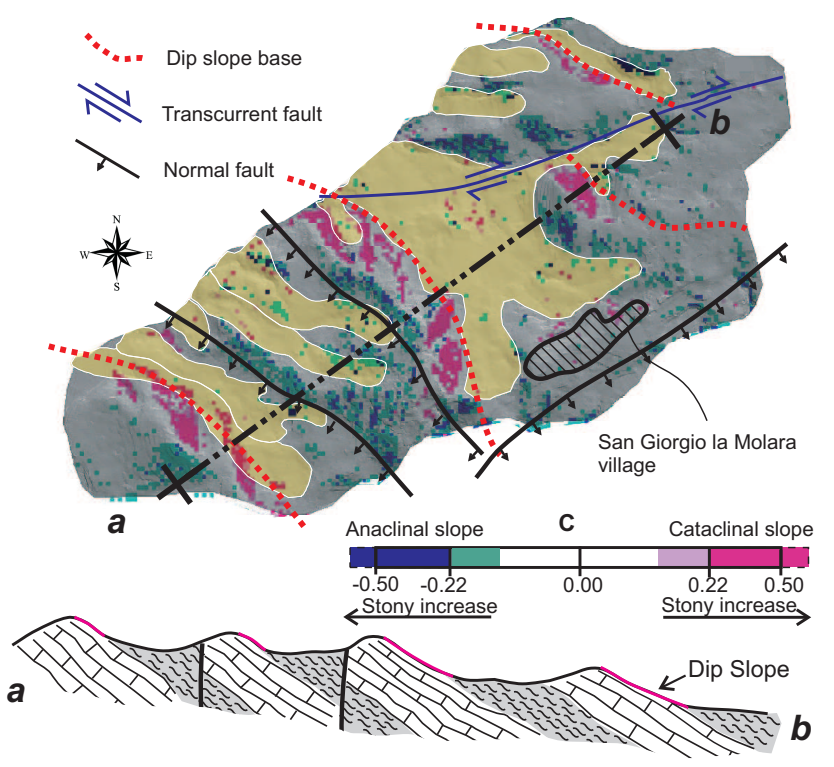

Fig. 18. Structural control operated by dip slopes and fault slope series and schematic cross-section of the geo-structural setting. Landslide are shown in yellow. $C$-index scale is also shown.

An "in series" structural control is recognized in Fig. 18. The $C$ index identifies a series of sandstone dip slopes orthogonal to the main slope and locally translated by normal or strike-slip faults. The sandstone banks provide a structural control on the development of landslides, which occur within the clayey member.

\section{Discussion and conclusion}

The proposed methodological procedure permits the obtainment of quantitative information regarding the control of litho-structural settings on slope evolution and landslide development. The bedding plain distribution is the main requirement for a mapping analysis. However, this distribution cannot be performed by the usual GIS interpolation techniques. This is due to both the geometrical nature of azimuth data and, more in general, to the real complexity of the geological setting.

Unlike continue azimuth interpolation techniques (e.g. de Kemp, 1998; Meentemeyer and Moody, 2000; Günther, 2003), NADIA operates both in continue and in discontinue modality in order to perform azimuth distribution and constitutes the base for mapping quantitative indexes related to structural control.

Specifically, NADIA considers both the directional nature of the angular datum and the possibility to implement discontinuous spatial distributions in the case of wide angular ranges, due to faults, folds and angular unconformities. Nevertheless, since discontinuities are only recognized by wide azimuth variations between adjoining point measurements without taking into account the bedding dip, this method may approach the actual setting in all but a few cases. For example, this might occur if folds with a high inclination of the axis $\left(>70-80^{\circ}\right)$ are present. In this case, changes in azimuth values actually happen in a continuous manner. If this is the case, fictitious strike/dip measurements could be added between real points with the aim of reducing the azimuth gap and therefore enabling NADIA to work continuously.

On this basis, the $\Delta$ index, which identifies the geometrical setting between slope and stratigraphic sequences, permits the analysis of some general behaviours. In the pilot area, among all the obtainable azimuth combinations, cataclinal slopes result in having the least distribution related 
to both the total slope surface and the landslide surface (Fig. 9b). This character suggests that bedding planes may not produce a predominant influence on landslide susceptibility in areas which are highly tectonized. This outcome is also supported by the similar mapping distribution of cataclinal and anaclinal slopes in relation to slope angle (Fig. 9c), where it seems that the common peaks can be related to the residual shear strength of the clayey component (Grelle and Guadagno, 2010). This aspect confers to this index a mechanical "threshold" condition, governing the mobility of landslide masses even where the stony component is dominant.

Structural control on landslide evolution and shape, and therefore on style and distribution of the activity, can be observed from the comparison between the $C$ distribution and landslide distribution. A decisive control role results when rocky layers within the sequences prevail whatever the orientation of bedding planes (cataclinal or anaclinal slope) may be.

Moreover, schematisation of some recurrent settings in relation to landslide occurrence and behaviour by means of the LSMs points out that tectonic structures in TC and BC sequences, which are locally characterized by a significant stony component, promote structural control conditions in different sectors of landslide bodies. In particular, depending on their abundance and orientation, stony levels may influence: (i) the retrogressive expansion of the source area, where, in addition, secondary falls, topples, translational slides or lateral spreads of rock blocks might occur; (ii) the channel zone, causing narrowing, flow deviation or jump as in the St. Andrea event (Fig. 13a); and iii) the accumulation modality and, therefore, the toe morphology. Landslides in IC sequences, where the stony component is poor or sparsely distributed, seem to not suffer the influence of both tectonic structures and bedding plane attitudes. These environments show a widespread landsliding, where mass movements represent the main morpho-evolutive factor characterised by coalescent landslide systems of entire basins.

This study contributes to highlighting that the structural control on landslides is a typical and characteristic factor in structurally complex formations. It influences susceptibility, magnitude and activity (in particular the distribution of the activity) of landslides. As a consequence, the approach introduced, which also permits detecting some control conditions in relation to behavioural base models (LSMs), may be used for spatial analyses of landslides and to indicate the most likely future behaviour in similar environmental contexts. In particular, it also provides the possibility for firstorder identification to be made of the spatial evolution of landslide bodies. Such identifications may become a useful tool for improved landslide susceptibility studies and hazard analysis in geologically complex areas.

Finally, future enhancements of NADIA are being developed directed toward improved deterministic susceptibility analyses in different geological environments.
Acknowledgements. The author would like to thank Rinaldo Genevois, Domenico Calcaterra, and an anonymous reviewer for useful and valuable comments. This work has been funded by the Benevento Province and the Department of Geological and Environmental Studies of the University of Sannio in Benevento (Italy)

Edited by: O. Katz

Reviewed by: R. Genevois and D. Calcaterra

\section{References}

Callaway, C.: On plagioclinal mountains, Geol. Mag., 15, 216-221, 1879.

Cruden, D. M.: Some Forms of Mountain Peaks in the Canadian Rockies Controlled by their Rock Structure, Quartern. Int., 6871, 59-65, 2000.

Cruden, D. M. and Hu, X. Q.: Hazardous modes of rock slope movement in the Canadian Rockies, Environ. Eng. Geosci., 2, 507-516, 1996.

Cruden, D. M., and Varnes, D. J.: Landslide Types and Processes, in: Landslides: Investigation and Mitigation, edited by: Turner A.R. e Shuster R. L. Sp. Rep., 247, Transportation Research Board, National Research Council, National Academy Press, Washington D.C., 36-72, 1996.

D’Argenio, B., Pescatore, T. S., and Scandone, P.: Schema geologico dell'Appennino Meridionale, Acc. Naz. Lincei, Quad. 183, 49-72, 1973.

de Kemp, E. A.: Three-dimensional projection of curvilinear geological features through direction cosine interpolation of structural field observations, Comput. Geosci., 24, 3, 269-284, 1998.

Davis, J. C.: Statistics and data analysis in geology: New York, John Wiley and Sons, (2nd ed.), 646 pp., 1986.

Environmental Systems Research Institute (ESRI): Arcview GIS 3.2., Environmental Systems Research Institute Inc., Redlands, California, USA, 1999.

Esu, F.: Behaviour of slopes in structurally complex formations, Proc. Int. Sym. on The Geotechnics of Structurally Complex Formations, Capri, 2, 292-304, 1977.

Fookes, P. G. and Wilson, D. D.: The geometry of discontinuities and slope failures in Siwalik Clay, Geotechnique, 16, 4, 305-320, 1966.

Grelle, G. and Guadagno, F. M.: Shear mechanisms and viscoplastic effects during impulsive shearing, Géotechnique, 60, 2, 91103, 2010.

Guadagno, F. M., Revellino, P., Grelle, G., and Lupo, G.: Structurally-controlled earth flows in Campania Apennines (Southern Italy), in: Landslides and Engineered Slopes, From the Past to the Future, edited by: Chen, Z., Zhang, J., Li, Z., Wu, F., Ho, K., Proc. of the 10th Int. Sym. on Landslides and Engineered Slopes, 30 June - 4 July 2008, Xi' an, China, Taylor and Francis Group, London, I, 365-371, , ISBN 978-0-415-4119672008, 2008

Guadagno, F. M., Focareta, M., Revellino, P., Bencardino, M., Grelle, G., Lupo, G., and Rivellini, G.: La carta delle frane della provincia di Benevento, Sannio University Press., Pubb. n. 2906/2006 of CNR-GNDCI, 2006.

Guzzetti, F., Cardinali, M., and Reichenbach, P.: The influence of structural setting and lithology on landslide type and pattern, En- 
viron. Eng. Geosci., 2, 4, 531-555, 1996.

Günther, A.: SLOPEMAP: programs for automated mapping of geometrical and kinematical properties of hard rock hill slopes, Comput. Geosci., 29, 865-875, 2003.

Irfan, T. Y.: Structurally controlled landslides in saprolitic soils in Hong Kong, Geotechnical and Geological Engineering, 14, 215238, 1998.

ISPRA: Foglio n 419 "San Giorgio la Molara". Nuova Carta Geologica d'Italia - scala 1:50.000. Progetto CAR.G. - Finanziamento Regione 1996, in press, 2011.

Margielewski, W.: Structural control and types of movements of rock mass in anisotropic rocks: Case studies in the Polish Flysch Carpathians, Geomorphology, 77, 47-68, 2006.

Martino, S., Moscatelli, M., and Scarascia Mugnozza, G.: Quaternary mass movements controlled by a structurally complex setting in the Central Apennines (Italy), Eng. Geol., 72, 33-55, 2004.

Meentemeyer, R. and Moody, A. W.: Automated mapping of conformity between topographic and geological surfaces, Comput. Geosci., 26, 815-829, 2000.

Patacca, E. and Scandone, P.: Late thrust propagation and sedimentary response in the thrust belt-foredeep system in the Southern Apennines (Pliocene-Pleistocene), in: Anatomy of an Orogen: The Apennines and Adjacent Mediterranean Basins, edited by: Vai, G. B. and Martini, I. P., Kluwer Academic Publ., 401-440, 2001.

Pescatore, T., Di Nocera, S., Matano, F., Pinto, F., Quarantiello, R., Amore, O., Boiano, U., Civile, D., Fiorillo, L., and Martino, C.: Geologia del settore centrale dei Monti del Sannio: nuovi dati stratigrafici e strutturali, Mem. Descr. Carta Geol. D'It., 77-94, 2008.
Powell, J. W.: Exploration of the Colorado River of the West and its Tributaries. Government Printing Office, Washington, DC, 291 pp., 1875.

Prager, C., Zangerl, C., and Nagler, T.: Geological controls on slope deformations in the Koefels Rockslide area (Tyrol, Austria), Austrian Journal of Earth Sciences, 102, 2, 4-19, 2009.

Revellino, P., Grelle, G., Donnarumma, A., and Guadagno, F. M.: Structurally-controlled earth flows of the Benevento Province (Southern Italy), Bull. Eng. Geol. Env., 69, 3, 487-500, doi:10.1007/s10064-010-0288-9, 2010.

Scheidegger, A. E.: Tectonic predesign of mass movements, with examples from the Chinese Himalaya, Geomorphology, 26, 37 46, 1998.

Servizio Geologico d'Italia: Carta geologica d'Italia alla scala 1:100.000. Foglio n. 173 Benevento", 1971.

Varnes, D. J.: Slope movement, types and processes, in: Landslides analysis and control, edited by: Schuster, R. L. and Krizek, R. J., Transportation Research Board, National Academy of Sciences, Washington, D.C., Special Report 176, 11-33, 1978.

Vv. Aa.: Geotechnical Engineering in Italy, An overview, Published on the occasion of the ISSMFE Golden Jubilee, Roma, A. G. I.Associazione Geotecnica Italiana, 414 pp., 1985.

WP/WLI: A Suggested Method for Describing the Activity of a Landslide, Bullettin of the I.A.E.G., 47, 53-57, 1993.

Zaruba, Q. and Mencl, V.: Landslides and their control, ElsevierAcademia Prague, 205 pp., 1969. 